Tohoku J. Exp. Med., 2011, 224, 91-97

\title{
Protective Effects of Anisodamine on Renal Function in Patients with ST-Segment Elevation Myocardial Infarction Undergoing Primary Percutaneous Coronary Intervention
}

\author{
Yanbo Wang, ${ }^{1}$ Xianghua Fu, ${ }^{1}$ Xuechao Wang, ${ }^{1}$ Xinwei Jia, ${ }^{1}$ Xinshun Gu, ${ }^{1}$ \\ Jing Zhang, Jianling Su, ${ }^{1}$ Guozhen Hao, ${ }^{1}$ Yunfa Jiang, ${ }^{1}$ Weize Fan, ${ }^{1}$ Weili $W u^{1}$ and \\ Shiqiang $\mathbf{L i}^{1}$
}

${ }^{1}$ Department of Cardiology, the Second Hospital of Hebei Medical University, Shijiazhuang, P.R. China

\begin{abstract}
ST-segment elevation myocardial infarction (STEMI) is the most severe type of heart attack, and primary percutaneous coronary intervention $(\mathrm{PCl})$ is the first line treatment for STEMI. However, these patients are at higher risk of contrast-induced nephropathy $(\mathrm{CIN})$, which increases the length of hospital stay and mortality rate. Anisodamine, an alkaloid extracted from a Chinese herb, has been shown to exert protective effects on the renal function. The aim of this study was to investigate the protective effect of anisodamine on CIN in STEMI patients undergoing primary $\mathrm{PCl}$. A total of 126 consecutive STEMI patients were randomly assigned to receive anisodamine $(n=60)$ or placebo (control, $n=66$ ) from admission to 24 hours after $\mathrm{PCl}$. The serum creatinine ( $\mathrm{SCr}$ ) concentrations, estimated glomerular filtration rate (eGFR) and incidence of CIN were measured on admission, and 24,48 and 72 hours after $\mathrm{PCl}$ between the two groups. We found that the renal function of all patients after $\mathrm{PCl}$ underwent a course from injury to recovery. The incidence of $\mathrm{CIN}$ was $5.0 \%, 8.3 \%$, and $6.7 \%$ at 24,48 and 72 hours, respectively, after primary $\mathrm{PCI}$ in anisodamine group, while in control group it was $16.7 \%, 22.7 \%$, and $19.7 \%$, respectively. The incidence of $\mathrm{CIN}$ in anisodamine group was lower than that in control group during 72 hours after $\mathrm{PCl}($ all $P<0.05$ ). In conclusion, intravenous infusion of anisodamine before and after primary $\mathrm{PCl}$ may reduce the occurrence of $\mathrm{CIN}$ in STEMI patients undergoing primary $\mathrm{PCl}$, without serious side effects.
\end{abstract}

Keywords: anisodamine; contrast induced nephropathy; percutaneous coronary intervention; serum creatinine; ST segment elevation myocardial infarction

Tohoku J. Exp. Med., 2011, 224 (2), 91-97. ㅇ 2011 Tohoku University Medical Press

Acute ST segment elevation myocardial infarction (STEMI), the most severe type of heart attack, usually occurs when thrombus forms on a ruptured athermanous plaque and occludes an epicardial coronary artery. Primary percutaneous coronary intervention (PCI) has been proven to be the best option to recanalize the artery for STEMI patients. However, because of the use of contrast medium, the STEMI patients undergoing primary PCI are at higher risk of contrast-induced nephropathy (CIN) than those undergoing elective interventions (Wickenbrock et al. 2009), which not only increases the duration of hospital stay, but is also associated with an increased mortality rate (Best et al. 2002; Lindsay et al. 2004). The different threshold criteria chosen for CIN will lead to varied rates of $6 \%-35 \%$ of inpatients exposed to iodinated contrast medium. Many studies have reported regarding the possible clinical factors that contribute to the development of CIN in STEMI patients (Sadeghi et al. 2003). Prior renal dysfunction, diabetes, impaired systemic perfusion due to left ventricular dysfunction, shock and dehydration, a large volume of contrast medium for complicated lesions (Marenzi et al. 2009), and the impossibility of starting renal prophylactic therapies before exposure to contrast medium are among the major factors that seem to be involved. As a result, more complicated clinical courses and significantly higher in-hospital mortality have been reported when CIN occurs after primary PCI, even in patients who present with normal renal function (Marenzi et al. 2004). Thus, there is a pressing need to find effective strategies to prevent it (Mautone and Brown 2010). Although several therapeutic approaches have been described to reduce the incidence of CIN, only hydration has been consistently shown to be effective (Kawashima et al. 2006; Kowalczyk et al. 2007).

Anisodamine, an alkaloid extracted from a Chinese herb, is vasoactive in relieving microvascular spasm, improving and dredging the microcirculation (Xiu et al.

Received January 13, 2011; revision accepted for publication April 26, 2011. doi: 10.1620/tjem.224.91

Correspondence: Xianghua Fu, M.D., Ph.D., FACC, Department of Cardiology, the Second Hospital of Hebei Medical University, Shijiazhuang 050000, P.R. China.

e-mail: fuxh999@hotmail.com 
1982), and increasing the tolerance to ischemia in patients with microcirculatory disorder. It is widely used in the treatment of septic shock, acute glomerulonephritis and diabetic nephropathy, and shows protective effects on the renal function (Poupko et al. 2007). However, to date no studies have focused on its preventive effect on CIN. This single blinded, placebo-controlled and randomized trial was to evaluate the effect of anisodamine on renal function in STEMI patients undergoing primary PCI.

\section{Materials and Methods}

\section{Study Population}

From January 2009 to June 2010, all consecutive STEMI patients within 12 hours from onset of symptoms undergoing primary PCI in the Cardiology Department of the Second Hospital of Hebei Medical University were enrolled. Inclusion criteria included typical clinical presentation, ST elevation of over $0.2 \mathrm{~mm}$ in two or more adjacent precordial leads or $0.1 \mathrm{~mm}$ in adjacent limb leads, and a rise of creatine kinase twice over the upper limit of normal status or an elevation of troponin I. The following exclusion criteria were used: cardiogenic shock, heart rate $>100 /$ min on admission, end-stage renal disease requiring dialysis, known allergic constitution, disagreement to participate in this study and other conditions which were not suitable for the use of anisodamine. The study protocol was approved by the Ethical Committee of the Second Hospital of Hebei Medical University. Informed consents were obtained from all the patients. All the protocol was in compliance with the Declaration of Helsinki.

\section{Study Protocols}

The diagnosis of STEMI was established according to symptoms of ischemia, ECG changes and part of biochemical examinations in all patients immediately after admission. Eligible patients were randomly assigned to receive anisodamine (anisodamine group, ANI) or placebo (control group, $\mathrm{CON}$ ) by means of random number table. Patients in the ANI group received anisodamine $50 \mu \mathrm{g} / \mathrm{kg}$ bolus injection after randomization followed by an adjusted-dose $(0.1-0.2 \mu \mathrm{g} / \mathrm{kg} /$ $\min$ ) to $24 \mathrm{~h}$ after PCI, while patients in CON received infusion of placebo $(0.9 \%$ sodium chloride) with the same volume of ANI group. Other medications were administered to all the patients (including aspirin, clopidogrel, diuretics, isotropic agents, intravenous vasodilator, statins, beta-blockade, angiotensin converting enzyme inhibitors, and anticoagulation agents) according to current best practice. Primary PCI was performed with standard technique as soon as possible. PCI success was defined as grade 3 flow of post-procedural thrombolysis in myocardial infarction (TIMI) and a decrease of residual stenosis to $<20 \%$ by quantitative coronary analysis. The nonionic contrast (Ultravist 370, iodine $370 \mathrm{mg} / \mathrm{ml}$, Schering Pharmaceutical Ltd., China) was used in all patients. Intravenous hydration was given to all patients with intravenous isotonic saline $(0.9 \%)$ at a rate of $1 \mathrm{ml} / \mathrm{kg} /$ hour or $0.5 \mathrm{ml} / \mathrm{kg} /$ hour in case of overt heart failure before the procedure and for 12 hours after the procedure. Left ventricular function was evaluated by echocardiography in all patients within 24 hours after admission. Investigators involved in the procedures and those reading echocardiograms were all blind to the randomized treatment. CIN is the acute deterioration of renal function defined as an increase in $\mathrm{SCr}>0.5 \mathrm{mg} / \mathrm{dl}(>44.2 \mu \mathrm{mol} / \mathrm{L})$ or $25 \%$ above baseline SCr value within 48-72 hours after PCI (Mehran and Nikolsky 2006). Serum creatinine ( $\mathrm{SCr}$ ) concentrations were measured at admission,
24 hours, 48 hours and 72 hours after PCI. Estimated glomerular filtration rate (eGFR) was calculated by the simplified modification of diet in renal disease study equation (MDRD): $\mathrm{eGFR}=186 \times$ Serum creatinine $^{-1.154} \times$ age $^{-0.203}($ female $\times 0.742)($ Levey et al. 2006).

\section{Statistic analysis}

All calculations were computed with the aid of SAS statistical software (version 8.02). The continuous variables were reported as means \pm S.D., and the categorical variables were presented as percentages. Continuous variables were compared using the $t$ test for normally distributed value; and the Mann-Whitney $U$ test was used. Proportions were compared using Fisher's exact test when the expected frequency was $<5$; and the chi-square test was applied. Multivariate test of repetitive measure ANOVA was used to compare the different serum creatinine levels, eGFR and heart rates before and after the procedure in each group. A $P$ value of less than 0.05 (2-tailed) was considered statistically significant.

\section{Baseline data}

\section{Results}

Of the 126 patients enrolled, 60 were randomly assigned to anisodamine and 66 to placebo. All patients received the assigned treatment. There were no significant differences in baseline characteristics, including mean age, gender distribution, risk factors, and clinical presentations between the two groups. The laboratory results and medications used during the procedure were not significantly different. The SCr concentration on admission and eGFR were also similar between the two groups. The preexisting chronic kidney disease (defined as eGFR $<60 \mathrm{ml} / \mathrm{min} / 1.73$ $\mathrm{m}^{2}$ ) was not different between the two groups (Table 1).

The average time of onset to balloon was similar between the two groups. There were no significant differences regarding the distribution of infarction related artery, interventions procedure, stent implantations, use of intravenous GP IIb/IIIa receptor antagonist, total contrast volume consumption and the hydration volume (Table 2).

\section{Changes of renal function after primary PCI}

Changes of $\mathrm{SCr}$. The $\mathrm{SCr}$ concentration at admission was not significantly different between the two groups (Table 3). However, it was lower in ANI group than that in CON group at hour 48 and 72 after administration of contrast medium $(91.1 \pm 19.4 \mu \mathrm{mol} / \mathrm{L}$ vs. $99.0 \pm 23.0 \mu \mathrm{mol} / \mathrm{L}$, $84.7 \pm 16.8 \mu \mathrm{mol} / \mathrm{L}$ vs. $93.7 \pm 28.3 \mu \mathrm{mol} / \mathrm{L}$, both $P<0.05$ ). For both groups, $\mathrm{SCr}$ concentrations significantly increased after PCI $(P<0.0001)$, with the peak value occurring at hour 48 , and then began to decrease. To be specific, in ANI group, $\mathrm{SCr}$ concentration decreased significantly $(84.9 \pm$ $16.8 \mu \mathrm{mol} / \mathrm{L}$ vs. $91.1 \pm 19.4 \mu \mathrm{mol} / \mathrm{L}, P<0.05)$ at hour 72 , and returned to baseline level $(84.9 \pm 16.8 \mu \mathrm{mol} / \mathrm{L}$ vs. 83.1 $\pm 17.7 \mu \mathrm{mol} / \mathrm{L}, P>0.05$ ), while in $\mathrm{CON}$ group, $\mathrm{SCr}$ concentration also decreased significantly $(93.7 \pm 28.3 \mu \mathrm{mol} / \mathrm{L}$ vs. $99.0 \pm 23.0 \mu \mathrm{mol} / \mathrm{L}, P<0.05)$ at hour 72 , but the result was still higher than baseline $(93.7 \pm 28.3 \mu \mathrm{mol} / \mathrm{L}$ vs. 82.2 $\pm 14.1 \mu \mathrm{mol} / \mathrm{L}, P<0.0001)$. 
Table 1. Baseline Characteristics of the Patients.

\begin{tabular}{|c|c|c|c|}
\hline & $\begin{array}{l}\text { ANI group } \\
(N=60)\end{array}$ & $\begin{array}{l}\text { CON group } \\
(N=66)\end{array}$ & $P$ value \\
\hline Age-yr & $56.9 \pm 11.2$ & $54.9 \pm 12.3$ & 0.344 \\
\hline Gender (male/female)-no. & $51 / 9$ & $57 / 9$ & 0.827 \\
\hline $\operatorname{BMI}\left(\mathrm{kg} / \mathrm{m}^{2}\right)$ & $25.1 \pm 3.1$ & $25.2 \pm 3.2$ & 0.138 \\
\hline Current smoking- no. (\%) & $36(60)$ & $31(47)$ & 0.143 \\
\hline Diabetes- no. $(\%)$ & $13(27.7)$ & $14(21.2)$ & 0.951 \\
\hline Hypertension- no. (\%) & $36(60.0)$ & $34(51.5)$ & 0.338 \\
\hline Dyslipidemia- no. (\%) & $15(25.0)$ & $13(19.7)$ & 0.475 \\
\hline Chronic kidney disease- no. (\%) & $1(1.7)$ & $2(3.0)$ & 0.612 \\
\hline Anterior infarction- no. (\%) & $29(48.3)$ & $35(53.0)$ & 0.598 \\
\hline \multicolumn{4}{|l|}{ Killip classification- no. (\%) } \\
\hline grade 1 & $44(73.3)$ & $43(65.1)$ & 0.321 \\
\hline grade 2 & $11(18.3)$ & $15(22.7)$ & 0.543 \\
\hline grade 3 & $5(8.3)$ & $8(12.1)$ & 0.485 \\
\hline LVEF (\%) & $60.3 \pm 9.5$ & $58.4 \pm 10.8$ & 0.299 \\
\hline \multicolumn{4}{|l|}{ Laboratory results } \\
\hline Peak CK-MB (U/L) & $179.4 \pm 129.3$ & $185.8 \pm 129.9$ & 0.784 \\
\hline Hemoglobin $(\mathrm{g} / \mathrm{L})$ & $136.5 \pm 14.3$ & $138.0 \pm 20.9$ & 0.642 \\
\hline Blood glucose (mmol/L) & $7.9 \pm 3.5$ & $8.2 \pm 3.2$ & 0.671 \\
\hline Baseline serum creatinine $(\mu \mathrm{mol} / \mathrm{L})$ & $83.1 \pm 17.7$ & $82.2 \pm 14.1$ & 0.577 \\
\hline Baseline eGFR $\left(\mathrm{ml} / \mathrm{min} / 1.73 \mathrm{~m}^{2}\right)$ & $91.2 \pm 23.1$ & $91.2 \pm 22.9$ & 0.993 \\
\hline \multicolumn{4}{|l|}{ Medications used during hospitalization } \\
\hline Beta-blockade- no. (\%) & $49(81.7)$ & $52(78.8)$ & 0.687 \\
\hline Angiotensin-converting enzyme inhibitor- no. (\%) & $40(66.7)$ & $41(60.6)$ & 0.595 \\
\hline Angiotensin receptor blocker- no. (\%) & $4(6.7)$ & $6(9.1)$ & 0.863 \\
\hline Diuretics- no. $(\%)$ & $5(8.3)$ & $7(10.6)$ & 0.664 \\
\hline Digitalis- no. (\%) & $4(6.7)$ & $5(7.6)$ & 0.843 \\
\hline
\end{tabular}

CK-MB, creatine kinase-MB; LVEF, left ventricular ejection fraction; BMI, Body mass index.

Table 2. Angiographic and procedural features.

\begin{tabular}{|c|c|c|c|}
\hline & $\begin{array}{l}\text { ANI group } \\
(N=60)\end{array}$ & $\begin{array}{l}\text { CON group } \\
(N=66)\end{array}$ & $P$ value \\
\hline Onset to balloon (hours) & $6.1 \pm 2.8$ & $5.9 \pm 2.9$ & 0.659 \\
\hline Onset to balloon $\leq 6 \mathrm{~h}-$ no. $(\%)$ & $39(65.0)$ & $43(65.2)$ & 0.986 \\
\hline Door to balloon (minutes) & $45.1 \pm 17.2$ & $43.8 \pm 16.3$ & 0.725 \\
\hline \multicolumn{4}{|l|}{ IRA- no. $(\%)$} \\
\hline LAD & $29(48.3)$ & $34(51.5)$ & 0.721 \\
\hline LCX & $13(21.7)$ & $10(15.2)$ & 0.344 \\
\hline $\mathrm{RCA}$ & $18(30.0)$ & $22(33.3)$ & 0.688 \\
\hline Stents used per patients (n) & $1.3 \pm 0.5$ & $1.3 \pm 0.6$ & 0.727 \\
\hline GPI- no. $(\%)$ & $27(45.0)$ & $24(36.4)$ & 0.329 \\
\hline Total contrast dose (ml) & $256.8 \pm 71.9$ & $259.8 \pm 79.1$ & 0.823 \\
\hline Contrast medium $\geq 300 \mathrm{ml}$ - no.(\%) & $17(28.3)$ & $24(36.4)$ & 0.337 \\
\hline Hydration volume (ml) & $774.0 \pm 212.4$ & $730.6 \pm 252.9$ & 0.302 \\
\hline
\end{tabular}

Onset to balloon, the time from chest pain onset to the first use of an intracoronary balloon during primary PCI.

Door to balloon, the time from admission to the first use of an intracoronary balloon during primary PCI.

IRA, infarction related artery; LAD, left anterior descending coronary artery; LCX, left circumflex coronary artery; RCA, right coronary artery; GPI, Glycoprotein IIb/IIIa receptor antagonist. 
Table 3. Changes of Scr and eGFR.

\begin{tabular}{llc}
\hline & $\begin{array}{c}\text { ANI group } \\
(N=60)\end{array}$ & $\begin{array}{c}\text { CON group } \\
(N=66)\end{array}$ \\
\hline SCr Concentration $(\mu \mathrm{mol} / \mathrm{L})$ & & $82.2 \pm 14.1$ \\
Baseline & $83.1 \pm 17.7$ & $91.1 \pm 18.6$ \\
24 hours after PCI & $84.0 \pm 21.2$ & $99.0 \pm 23.0^{\dagger}$ \\
48 hours after PCI & $91.1 \pm 19.4^{*}$ & $93.7 \pm 28.3^{\dagger \ddagger}$ \\
72 hours after PCI & $84.9 \pm 16.8^{*}$ & \\
eGFR $\left(\mathrm{ml} / \mathrm{min} / 1.73 \mathrm{~m}^{2}\right)$ & & $91.2 \pm 22.9$ \\
Baseline & $91.2 \pm 23.1$ & $81.0 \pm 20.3$ \\
24 hours after PCI & $90.5 \pm 21.0^{*}$ & $74.3 \pm 19.5^{\dagger}$ \\
48 hours after PCI & $82.0 \pm 16.7^{*}$ & $80.8 \pm 22.1^{\dagger *}$ \\
\hline 2 hours after PCI & $91.6 \pm 19.0^{* \ddagger}$ & \\
\hline
\end{tabular}

*compared to CON group at the same time point, $P<0.05$.

†compared to baseline, $P<0.0001$.

tcompared to 48 hours after PCI in ANI group, $P<0.05$.

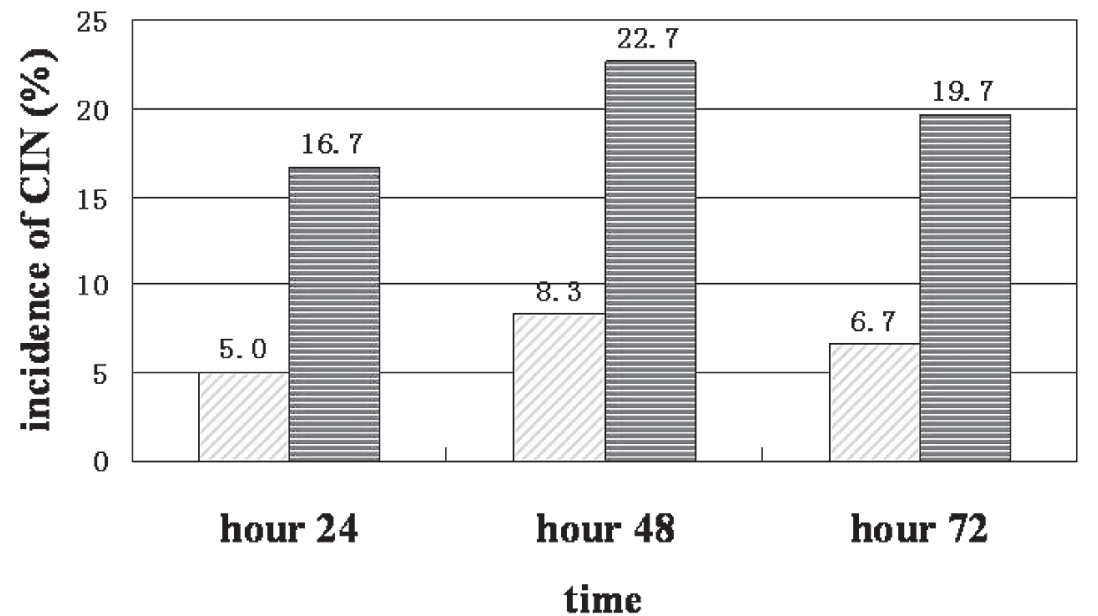

ANI group 国 CON group

Fig 1. Incidence of CIN at different time.

Shown are the incidences of CIN at the indicated hours after primary PCI in anisodamine (ANI) group and control (CON) group. Compared to CON group, $P<0.05$ at each time point.

Changes of eGFR. The eGFR at admission was also similar between the two groups (Table 3). The eGFR at hour 24, 48 and 72 after primary PCI were higher in ANI group than those in control group $(90.5 \pm 21.0 \mathrm{ml} / \mathrm{min} / 1.73$ $\mathrm{m}^{2}$ vs. $81.0 \pm 20.3 \mathrm{ml} / \mathrm{min} / 1.73 \mathrm{~m}^{2}, 82.0 \pm 16.7 \mathrm{ml} / \mathrm{min} / 1.73$ $\mathrm{m}^{2}$ vs. $74.3 \pm 19.5 \mathrm{ml} / \mathrm{min} / 1.73 \mathrm{~m}^{2}, 91.6 \pm 19.0 \mathrm{ml} / \mathrm{min} / 1.73$ $\mathrm{m}^{2}$ vs. $80.8 \pm 22.1 \mathrm{ml} / \mathrm{min} / 1.73 \mathrm{~m}^{2}$, all $P<0.05$ ). In ANI group, eGFR increased significantly at hour 72 compared with that at hour $48\left(91.6 \pm 19.0 \mathrm{ml} / \mathrm{min} / 1.73 \mathrm{~m}^{2}\right.$ vs. $82.0 \pm$ $16.7 \mathrm{ml} / \mathrm{min} / 1.73 \mathrm{~m}^{2}, P<0.05$ ), and the result was similar to the baseline level $\left(91.6 \pm 19.0 \mathrm{ml} / \mathrm{min} / 1.73 \mathrm{~m}^{2}\right.$ vs. $91.2 \pm$ $\left.23.1 \mathrm{ml} / \mathrm{min} / 1.73 \mathrm{~m}^{2}, P>0.05\right)$. In CON group, eGFR increased significantly $\left(80.8 \pm 22.1 \mathrm{ml} / \mathrm{min} / 1.73 \mathrm{~m}^{2}\right.$ vs. 74.3 $\left.\pm 19.5 \mathrm{ml} / \mathrm{min} / 1.73 \mathrm{~m}^{2}, P<0.0001\right)$ at hour 72 , but was still lower than baseline level $\left(80.8 \pm 22.1 \mathrm{ml} / \mathrm{min} / 1.73 \mathrm{~m}^{2} \mathrm{vs}\right.$. $\left.91.2 \pm 22.9 \mathrm{ml} / \mathrm{min} / 1.73 \mathrm{~m}^{2}, P<0.0001\right)$.

\section{Incidence of CIN}

The incidence of CIN was $5.0 \%, 8.3 \%$, and $6.7 \%$ at hour 24, 48 and 72, respectively, after primary PCI in ANI group, while in CON group it was $16.7 \%, 22.7 \%$, and $19.7 \%$, respectively (Fig. 1). The incidence of CIN in ANI group was lower than that in CON group within 72 hours after the procedure (all $P<0.05$ ). Dialysis was not used in both groups.

\section{Safety evaluation}

No palpitation, thirst, blurred vision and retention of urine were found in all the patients. There was a mild increase of heart rate after administration of anisodamine 
Table 4. Comparison of Heart Rate Changes between the two groups.

\begin{tabular}{|c|c|c|c|c|}
\hline & $\begin{array}{l}\text { Baseline } \\
\text { (beats/min) }\end{array}$ & $\begin{array}{l}\text { Three minutes after bolus } \\
\text { of anisodamine } \\
\text { (beats } / \mathrm{min} \text { ) }\end{array}$ & $\begin{array}{l}\text { Mean heart rates during } \\
\text { intravenous anisodamine } \\
\text { infusion (beats } / \mathrm{min} \text { ) }\end{array}$ & $\begin{array}{l}\text { Six hours after withdrawal } \\
\text { of anisodamine } \\
\text { (beats } / \mathrm{min} \text { ) }\end{array}$ \\
\hline $\begin{array}{l}\text { ANI group } \\
(N=60)\end{array}$ & $73.0 \pm 12.3$ & $87.0 \pm 16.1^{* \pi}$ & $76.4 \pm 9.1^{* \Uparrow \sharp}$ & $68.2 \pm 10.8^{\ddagger}$ \\
\hline $\begin{array}{l}\text { CON group } \\
(N=66)\end{array}$ & $72.9 \pm 11.2$ & $71.0 \pm 12.3$ & $70.7 \pm 11.8$ & $68.0 \pm 12.6$ \\
\hline
\end{tabular}

* compared to CON group, $P<0.05$.

"compared to baseline, $P<0.05$.

compared to peak heart rates, $P<0.05$.

$(73.0 \pm 12.3$ beats $/ \mathrm{min}$ vs. $76.4 \pm 9.1$ beats $/ \mathrm{min}, P<0.05)$, and the peak value occurred after bolus of anisodamine ( $73.0 \pm 12.3$ beats $/ \mathrm{min}$ vs. $87.0 \pm 16.1$ beats $/ \mathrm{min}, P<0.05)$, and recovered 6 hours later after withdrawal of anisodamine (Table 4). No malignant arrhythmia (defined as ventricular fibrillation or ventricular tachycardia with hemodynamic compromise requiring defibrillation) occurred in any patients.

\section{Discussion}

Our study demonstrated the protective effect of anisodamine on renal function in STEMI patients undergoing primary PCI. With anisodamine infusion, the renal function was not only less destroyed, but recovered better than that in control group. The incidence of CIN was also lower in ANI group than that in CON group.

Growing evidence indicates that primary PCI is the most effective treatment of STEMI (Widimsky et al. 2007; Fosbøl et al. 2008). However, patients with STEMI treated with primary PCI are at higher risk of CIN than those undergoing elective interventions, even in patients with normal baseline renal function. Several conditions may contribute to the development of renal dysfunction, such as vasoconstrictive factors resulting in medulla ischemia, decreased production of local prostaglandin-mediated vasodilatation, and the damage caused by oxygen radicals.

A large number of drugs have been used to protect renal function after PCI, such as aminophylline (Shammas et al. 2001; Rohani 2010), theophylline (Wang et al. 2001), atrial natriuretic peptide (Chen 2009; Morikawa et al. 2009), B-type natriuretic peptide (Zhang et al. 2010), mannitol (Kelly et al. 2008), prostaglandins (McCullough and Tumlin 2009), N-acetylcysteine (Thiele et al. 2010), sodium bicarbonate (Masuda 2008) and statins (Xinwei et al. 2009); however, few of them (Kowalczyk et al. 2007; Zoungas et al. 2009) have shown exact protective effects.

Anisodamine, a blocker of M-choline receptor, possesses the effect of improving microcirculation. Since 1980s, many basic and clinical studies in China have proven that it has produce significant protective effects on microcirculatory disorder. The previous studies found that intracoronary administration of $1,000 \mu \mathrm{g}$ anisodamine was effective in reversing coronary no-reflow phenomenon dur- ing primary PCI in STEMI patients and this effect may be due to improving coronary microcirculation ( $\mathrm{Fu}$ et al. 2007). In recent years, anisodamine is widely used in the treatment of septic shock, acute glomerulonephritis and diabetic nephropathy because of its protective effects on many organs, especially on kidney.

Anisodamine exerts renal protection via following mechanisms: anisodamine can dilate the arcuate artery, interlobular artery and afferent arteriole of kidney in a dose dependent manner. The glomerular blood flow increases by $15 \%-40 \%$ after administration of anisodamine. The use of anisodamine ameliorates the damages of renal microvessels and tissue structure, and is a potent vasodilator of preglomerular renal vessels, which can improve renal tissue ischemia (Zou et al. 1990). Anisodamine is also helpful in the recovery of renal blood flow in renal tissues by increasing the level of plasma PGI. In diabetes, anisodamine can improve renal hemodynamic and increase blood flow. Anisodamine could alleviate $\mathrm{Ca}^{2+}$-overload in renal histocytes in acute ischemic renal failure, and the mechanism is associated with intracellular reduction of inositol 1, 4, 5-triphosphate $\left(\mathrm{IP}_{3}\right)$ (Liu and Zhang 1998; Norby and Ren 2002). The renal protective effects of anisodamine may also be associated with activating super oxide dismutase (SOD) in renal tissues, decreasing the level of malondialdehyde (MDA), inhibiting expression of endothelin and apoptosis of renal cells (Nakagawa et al. 2005). Recently, some studies have shown that anisodamine could enhance spontaneous vasomotion of microvessels, accelerate the velocity of blood flow, and reduce the permeability of microvascular, which is beneficial for improving microcirculation of kidney. All above mechanisms of anisodamine may contribute to the prevention of $\mathrm{CIN}$, although the exact mechanism needs further studies.

The metabolism of anisodamine is mainly through the kidney, and its onset peak half-life is 1 minute and clearance half-life is 15 minutes. In this study, intravenous infusion of anisodamine for 24 hours after bolus injection maintained a stable plasma concentration of anisodamine. This dose of anisodamine exerted obvious renal protection and myocardial protection (our previous study results) at the cost of mild heart rate increase ( $5-15$ beats $/ \mathrm{min})$. No malignant arrhythmia, thirst, retention of urine, blurred vision 
during the treatment, which reflected the security of anisodamine.

To the best of our knowledge, this is the first study to investigate the renal protective effects of anisodamine on CIN. In this study, either SCr or eGFR was used as an indicator to evaluate the changes of renal function. The findings all indicated that the treatment with anisodamine is effective in protecting renal function. Not only can it alleviate renal injury, but also facilitate the early recovery of renal function.

The limitations of this study were small population of the STEMI patients undergoing primary PCI, and the short duration of observation. Although CIN often occurs within 48-72 hours after contrast exposure, it also can occur at any time within 7 days after PCI; thus, extending the observation period to 7 days may have improved the results.

In conclusion, the results support the renal protective effect of anisodamine, which can reduce the incidence of CIN in STEMI patients undergoing primary PCI without serious side effects.

\section{Conflict of Interest}

No conflicts of interest in connection with this article.

\section{References}

Best, P.J., Lennon, R., Ting, H.H., Bell, M.R., Rihal, C.S., Holmes, D.R. \& Berger, P.B. (2002) The impact of renal insufficiency on clinical outcomes in patients undergoing percutaneous coronary interventions. J. Am. Coll. Cardiol., 39, 1113-1119.

Chen, H.H. (2009) Atrial Natriuretic Peptide for the Prevention of Contrast-Induced Nephropathy: What's Old Is New But at the Right Dose and Duration of Therapy. J. Am. Coll. Cardiol., 53, 1047-1049.

Fosbøl, E.L., Thune, J.J., Kelbaek, H., Andersen, H.R., Saunamäki, K., Nielsen, T.T., Mortensen, L.S. \& Køber, L.; DANAMI-2 Investigators. (2008) Long-term outcome of primary angioplasty compared with fibrinolysis across age groups: a Danish Multicenter Randomized Study on Fibrinolytic Therapy Versus Acute Coronary Angioplasty in Acute Myocardial Infarction (DANAMI-2) substudy. Am. Heart J., 156, 391-396.

Fu, X.H., Fan, W.Z., Gu, X.S., Wei, Y.Y., Jiang, Y.F., Wu, W.L., Li, S.Q., Hao, G.Z., Wei, Q.M. \& Xue, L. (2007) Effect of intracoronary administration of anisodamine on slow reflow phenomenon following primary percutaneous coronary intervention in patients with acute myocardial infarction. Chin. Med. J . (Engl)., 120, 1226-1231.

Kawashima, S., Takano, H., Iino, Y., Takayama, M. \& Takano, T. (2006) Prophylactic Hemodialysis Does Not Prevent Contrast-Induced Nephropathy after Cardiac Catheterization in Patients with Chronic Renal Insufficiency. Circ. J., 70, 553-558.

Kelly, A.M., Dwamena, B., Cronin, P., Bernstein, S.J. \& Carlos, R.C. (2008) Meta-analysis: effectiveness of drugs for preventing contrast-induced nephropathy. Ann. Intern. Med., 148, 284-294.

Kowalczyk, J., Lenarczyk, R., Kowalski, O., Sredniawa, B., Musialik-Lydka, A., Gasior, M., Polonski, L., Zembala, M., Gumprecht, J. \& Kalarus, Z. (2007) Different types of renal dysfunction in patients with acute myocardial infarction treated with percutaneous coronary intervention. J. Interv. Cardiol., 20, 143-152.

Levey, A.S., Coresh, J., Greene, T., Stevens, L.A., Zhang, Y.L.,
Hendriksen, S., Kusek, J.W. \& Van Lente, F.; Chronic Kidney Disease Epidemiology Collaboration. (2006) Using standardized serum creatinine values in the modification of diet in renal disease study equation for estimating glomerular filtration rate. Ann. Intern. Med., 145, 247-254.

Lindsay, J., Canos, D.A., Apple, S., Pinnow, E., Aggrey, G.K. \& Pichard, A.D. (2004) Causes of acute renal dysfunction after percutaneous coronary intervention and comparison of late mortality rates with postprocedure rise of creatine kinase-MB versus rise of serum creatinine. Am. J. Cardiol., 94, 786-789.

Liu, X. \& Zhang, J. (1998) An experimental study on the mechanism of anisodamini hydrobromidum in treating acute ischemic renal failure. J. Tongji Med. Univ., 18, 187-189.

Marenzi, G., Assanelli, E., Campodonico, J., Lauri, G., Marana, I., De Metrio, M., Moltrasio, M., Grazi, M., Rubino, M., Veglia, F., Fabbiocchi, F. \& Bartorelli, A.L. (2009) Contrast volume during primary percutaneous coronary intervention and subsequent contrast-induced nephropathy and mortality. Ann Intern. Med., 150, 170-177.

Marenzi, G., Lauri, G., Assanelli, E., Campodonico, J., De Metrio, M., Marana, I., Grazi, M., Veglia, F. \& Bartorelli, A.L. (2004) Contrast-induced nephropathy in patients undergoing primary angioplasty for acute myocardial infarction. J. Am. Coll. Cardiol., 44, 1780-1785.

Masuda, M., Yamada, T., Okuyama, Y., Morita, T., Sanada, S., Furukawa, Y., Tsukamoto, Y., Okuda, K., Iwasaki, Y., Yasui, T. \& Fukunami, M. (2008) Sodium bicarbonate improves longterm clinical outcomes compared with sodium chloride in patients with chronic kidney disease undergoing an emergent coronary procedure. Circ. J., 72, 1610-1614.

Mautone, A. \& Brown, J.R. (2010) Contrast-induced nephropathy in patients undergoing elective and urgent procedures. $J$. Interv. Cardiol., 23, 78-85.

McCullough, P.A. \& Tumlin, J.A. (2009) Prostaglandin-based renal protection against contrast-induced acute kidney injury. Circulation, 120, 1749-1751.

Mehran, R. \& Nikolsky, E. (2006) Contrast-induced nephropathy: definition, epidemiology, and patients at risk. Kidney Int. Suppl., 100, S11-15.

Morikawa, S., Sone, T., Tsuboi, H., Mukawa, H., Morishima, I., Uesugi, M., Moritav, Y., Numaguchi, Y., Okumura, K. \& Murohara, T. (2009) Renal protective effects and the prevention of contrast-induced nephropathy by atrial natriuretic peptide. J. Am. Coll. Cardiol., 53, 1040-1046.

Nakagawa, S., Kushiya, K., Taneike, I., Imanishi, K., Uchiyama, T. \& Yamamoto, T. (2005) Specific inhibitory action of anisodamine against a Staphylococcal superantigenic toxin, toxic shock syndrome toxin 1 (TSST-1), leading to down-regulation of cytokine production and blocking of TSST-1 toxicity in mice. Clin. Diagn. Lab. Immunol., 12, 399-408.

Norby, F.L. \& Ren, J. (2002) Anisodamine inhibits cardiac contraction and intracellular $\mathrm{Ca} 2+$ transients in isolated adult rat ventricular myocytes. Eur. J. Pharmacol., 439, 21-25.

Poupko, J.M., Baskin, S.I. \& Moore, E. (2007) The pharmacological properties of anisodamine. J. Appl. Toxicol., 27, 116-121.

Rohani, A. (2010) Effectiveness of aminophylline prophylaxis of renal impairment after coronary angiography in patients with chronic renal insufficiency. Indian J. Nephrol., 20, 80-83.

Sadeghi, H.M., Stone, G.W., Grines, C.L., Mehran, R., Dixon, S.R., Lansky, A.J., Fahy, M., Cox, D.A., Garcia, E., Tcheng, J.E., Griffin, J.J., Stuckey, T.D., Turcov, M. \& Carroll, J.D. (2003) Impact of renal insufficiency in patients undergoing primary angioplasty for acute myocardial infarction. Circulation, 108, 2769-2775.

Shammas, N.W., Kapalis, M.J., Harris, M., Mckinney, D. \& Coyne, E.P. (2001) Aminophylline does not protect against radiocontrast nephropathy in patients undergoing percutaneous angiographic procedures. J. Invasive Cardiol., 13, 738-740.

Thiele, H., Hildebrand, L., Schirdewahn, C., Eitel, I., Adams, V., 
Fuernau, G., Erbs, S., Linke, A., Diederich, K.W., Nowak, M., Desch, S., Gutberlet, M. \& Schuler, G. (2010) Impact of highdose $\mathrm{N}$-acetylcysteine versus placebo on contrast-induced nephropathy and myocardial reperfusion injury in unselected patients with ST-segment elevation myocardial infarction undergoing primary percutaneous coronary intervention. The LIPSIA-N-ACC (Prospective, Single-Blind, PlaceboControlled, Randomized Leipzig Immediate Percutaneous Coronary Intervention Acute Myocardial Infarction N-ACC) Trial. J. Am. Coll. Cardiol., 55, 2201-2209.

Wang, Y.X., Jia, Y.F., Chen, K.M. \& Morcos, S.K. (2001) Radiographic contrast media induced nephropathy: experimental observations and the protective effect of calcium channel blockers. Br. J. Radiol., 74, 1103-1108.

Wickenbrock, I., Perings, C., Maagh, P., Quack, I., van Bracht, M., Prull, M.W., Plehn, G., Trappe, H.J. \& Meissner, A. (2009) Contrast medium induced nephropathy in patients undergoing percutaneous coronary intervention for acute coronary syndrome: differences in STEMI and NSTEMI. Clin. Res. Cardiol., 98, 765-772.

Widimsky, P., Bilkova, D., Penicka, M., Novak, M., Lanikova, M., Porizka, V., Groch, L., Zelizko, M., Budesinsky, T. \& Aschermann, M.; PRAGUE Study Group Investigators. (2007) Long-term outcomes of patients with acute myocardial infarction presenting to hospitals without catheterization laboratory and randomized to immediate thrombolysis or interhospital transport for primary percutaneous coronary intervention.
Five years' follow-up of the PRAGUE-2 Trial. Eur. Heart J., 28, 679-684.

Xinwei, J., Xianghua, F., Jing, Z., Xinshun, G., Ling, X., Weize, F., Guozhen, H., Yunfa, J., Weili, W. \& Shiqiang, L. (2009) Comparison of usefulness of simvastatin $20 \mathrm{mg}$ versus $80 \mathrm{mg}$ in preventing contrast-induced nephropathy in patients with acute coronary syndrome undergoing percutaneous coronary intervention. Am. J. Cardiol., 104, 519-524.

Xiu, R.J., Hammerschmidt, D.E., Coppo, P.A. \& Jacob, H.S. (1982) Anisodamine inhibits thromboxane synthesis, granulocyte aggregation, and platelet aggregation. A possible mechanism for its efficacy in bacteremic shock. JAMA, 247, 14581460.

Zhang, J., Fu, X., Jia, X., Fan, X., Gu, X., Li, S., Wu, W., Fan, W., Su, J., Hao, G., Jiang, Y. \& Xue, L. (2010) B-type natriuretic peptide for prevention of contrast-induced nephropathy in patients with heart failure undergoing primary percutaneous coronary intervention. Acta Radiologica, 51, 641-648.

Zou, A.P., Parekh, N. \& Steinhausen, M. (1990) Effect of anisodamine on the microcirculation of the hydronephrotic kidney of rats. Int. J. Microcirc. Clin. Exp., 9, 285-296.

Zoungas, S., Ninomiya, T., Huxley, R., Cass, A., Jardine, M., Gallagher, M., Patel, A., Vasheghani-Farahani, A., Sadigh, G. \& Perkovic, V. (2009) Systematic review: sodium bicarbonate treatment regimens for the prevention of contrast-induced nephropathy. Ann. Intern. Med., 151, 631-638. 